\title{
BMJ Open Quality Focusing on the penultimate step: increasing early lung transplant discussion in cystic fibrosis clinic to prepare patients for referral
}

\author{
Bethany L Bartley (D) , ${ }^{1}$ Anita St. John, ${ }^{1}$ Isabel P Neuringer, ${ }^{2}$ Brian M Cummings, ${ }^{3}$ \\ Lael M Yonker ${ }^{1}$
}

To cite: Bartley BL, St. John A, Neuringer IP, et al. Focusing on the penultimate step: increasing early lung transplant discussion in cystic fibrosis clinic to prepare patients for referral. BMJ Open Quality 2020;9:e001031. doi:10.1136/ bmjoq-2020-001031

This study was previously presented as an abstract at the 2019 North American Cystic Fibrosis Conference.

Received 25 May 2020 Revised 14 August 2020 Accepted 17 August 2020

\section{D) Check for updates}

(c) Author(s) (or their employer(s)) 2020. Re-use permitted under CC BY-NC. No commercial re-use. See rights and permissions. Published by BMJ.

${ }^{1}$ Pediatric Pulmonology, Massachusetts General Hospital, Boston, Massachusetts, USA ${ }^{2}$ Pulmonology, Massachusetts General Hospital, Boston, Massachusetts, USA

${ }^{3}$ Pediatric Critical Care Medicine, Massachusetts General Hospital, Boston, Massachusetts, USA

Correspondence to Dr Lael M Yonker; lyonker@mgh.harvard.edu

\section{INTRODUCTION}

Lung transplant is a potential life-lengthening option for individuals with cystic fibrosis $(\mathrm{CF})$ and advanced lung disease. However, referral for transplant evaluation is not made for the majority of patients with $\mathrm{CF}$ with low lung function who die each year. ${ }^{1}$ Recently published consensus guidelines from the CF Foundation identify early transplant discussion as a critical approach to optimise access to this treatment option. ${ }^{2}$ This quality improvement (QI) intervention sought to improve education of patients with $\mathrm{CF}$ regarding transplant by increasing the frequency of outpatient CF clinic visits in which transplant is discussed with patients with low lung function.

\section{METHODS}

The setting for the QI initiative was the paediatric CF Centre at Massachusetts General Hospital. Strategies included: (1) Assembly of a multidisciplinary QI team including nursing, social work, CF providers and a transplant physician, (2) Analysis of the baseline frequency of transplant discussion between $\mathrm{CF}$ providers and patients with low lung function (eg, forced expiratory volume in $1 \mathrm{~s}\left(\mathrm{FEV}_{1}\right) \leq 50 \%$-predicted), (3) Process mapping steps to lung transplant discussion during clinic visits, (4) Survey of CF providers $(n=3)$ to identify specific barriers to discussion in patients with low lung function, (5) Survey of patients with CF $(n=6)$ regarding optimal timing for initial discussion, (6) Brainstorming of potential interventions using a priority pay-off matrix, (7) Creation of a web-based intervention and patient education material, and (8) Postintervention data collection and analysis using standard statistics and QI methodology.
The project was undertaken as a QI initiative and was not formally supervised by the institutional review board of Mass General Brigham per their policies. Patients were involved in project design through individual interview and survey which guided the intervention.

Baseline data revealed 17 patients with $\mathrm{CF}$ with an $\mathrm{FEV}_{1} \leq 50 \%$-predicted, with a mean (SD) age of $30 \pm 12$ years (this paediatric centre also follows adults), $53 \%$ male, $94 \%$ white/ non-Hispanic and mean (SD) of $4 \pm 2 \mathrm{CF}$ clinic visits per year. Transplant was discussed and documented during $6 \%$ of clinic visits with this population during routine outpatient CF care over the prior year (figure 1).

Barriers to transplant discussion identified by CF providers from a prespecified list included: patient stability $(25 \%)$, concern for poor candidacy (25\%), concern for eliciting patient anxiety $(17 \%)$ and lack of time during visits with more active issues to discuss $(8 \%)$. Conversely, from the perspective of patients with CF, a majority (67\%) of individuals with CF (or their caregivers) stated they think about whether they will someday need a transplant and wanted to discuss transplant as a treatment option with their CF provider during a routine clinic visit, regardless of lung function.

From these diagnostic data, a specific aim was generated to increase the percentage of outpatient CF clinic visits in which transplant is discussed and documented with patients with low lung function (eg, $\mathrm{FEV}_{1}$ $\leq 50 \%$-predicted) from the baseline mean of $6 \%$ to $25 \%$ over 3 months. This aim was validated externally with the CF Foundation clinical care guidelines which state that individuals with $\mathrm{CF}$ should be seen at their $\mathrm{CF}$ centre quarterly, ${ }^{3}$ and transplant should 


\section{Percentage of outpatient $\mathrm{CF}$ clinic visits ( $\mathrm{FEV}_{1} \leq 50 \%$-predicted) with lung transplant discussed} (June 2018 - December 2019) - P Chart, 3 sigma

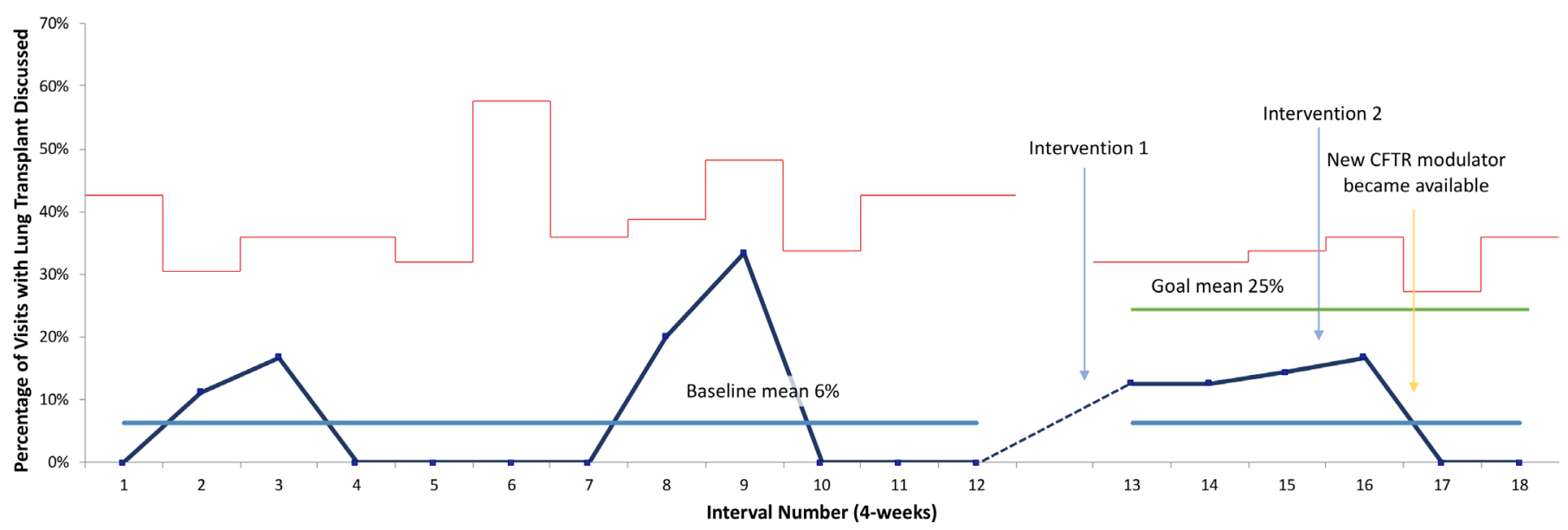

Figure 1 Statistical process control chart demonstrating the change over time in the frequency of lung transplant discussion between cystic fibrosis (CF) providers and patients with low lung function (dark blue line). The baseline mean is shown in light blue. The red line shows the upper control limit (UCL) which is 3 SD above the mean. The timing of the first and second interventions are shown with light blue arrows. The timing of the availability of a new CFTR modulator therapy (ElexacaftorTezacaftor-Ivacaftor) is shown with a yellow arrow. Baseline data are connected to postintervention data with a dotted line. The goal mean is shown in green. $\mathrm{FEV}_{1}$, forced expiratory volume in $1 \mathrm{~s}$.

be discussed annually after a patient's $\mathrm{FEV}_{1}$ falls below $50 \%$-predicted. ${ }^{2}$

Following intervention brainstorming, our multidisciplinary team developed a video-based educational tool addressing frequently asked questions about lung transplant in CF, as well as a list of medical tests commonly performed during transplant evaluation with plainlanguage explanations. Both resources were posted to our centre's website. Web content was reviewed with CF providers and providers were encouraged to use these resources with their patients during routine visits. The frequency of transplant discussion during outpatient visits was prospectively evaluated.

\section{RESULTS}

Over the 3-month interval from mid-June to midSeptember 2019, the frequency of transplant discussion increased from a baseline mean of $6 \%$ to $13 \%$ (figure 1).

Two additional systems-based changes were then implemented: reminders and triggers for transplant discussion. The reminder consisted of posters placed in exam rooms encouraging patients to ask questions about transplant during their visit. The trigger consisted of identifying pulmonary function tests if the patient's $\mathrm{FEV}_{1}$ recorded $\leq 50 \%$-predicted at the start of the visit so the provider would be notified. After the first month, the frequency of transplant discussion increased to a high of $17 \%$.

\section{DISCUSSION}

Previous studies have identified significant CF providerlevel ${ }^{45}$ and patient-level ${ }^{6}$ barriers to transplant referral for individuals with CF. This QI effort focused on the penultimate step of transplant discussion between CF providers and patients, specifically promoting patient education to medically and psychologically prepare patients for potential referral. Given the majority of CF providers use $\mathrm{FEV}_{1}$ to guide referral to a lung transplant programme ${ }^{45}$ and $\mathrm{CF}$ Foundation guidelines use specific lung function thresholds for recommendations on the timing of transplant discussion and referral, ${ }^{2}$ we mirrored these recommendations using $\mathrm{FEV}_{1} \leq 50 \%$-predicted as the threshold to initiate transplant discussion in our study.

The frequency of transplant discussion increased between CF providers and patients with low lung function using self-generated, patient education material and systems-based reminders in clinic. Our first intervention employed the change concept of giving individuals (providers) access to information, ${ }^{7}$ allowing the foundation for the second intervention with reminders and triggers. Initially this sequential approach proved effective; however notably, a highly effective CF-specific therapy, Elexacaftor-Tezacaftor-Ivacaftor, ${ }^{8}$ became available for the majority of patients followed in our CF programme in the latter half of the second intervention. As a result, providers prioritised the initiation of this promising new therapy over transplant discussion.

Although significant medical advances in CF care have taken place over the last few years with the advent of cystic fibrosis transmembrane conductance regulator (CFTR) modulators including Elexacaftor-Tezacaftor-Ivacaftor, ${ }^{8-10}$ many individuals with CF on CFTR modulator therapy continue to exhibit a decline in lung function over time, although at a slower rate. ${ }^{11}$ Additionally, roughly $10 \%$ of the CF population does not have qualifying mutations for CFTR modulator therapy, underscoring the importance of continued early lung transplant discussion in the CF care setting. 


\section{CONCLUSION}

Early lung transplant discussion remains critical for individuals with CF and advanced lung disease. Systemsbased reminders and triggers may improve the frequency of transplant discussion in CF clinic however, emerging therapies and their promise disrupted this important discussion and new efforts will be needed for the $\mathrm{CF}$ community.

Acknowledgements The authors thank the multidisciplinary CF Care Team at Massachusetts General Hospital for their involvement in this QI intervention. The authors specifically thank Dr Allen Lapey for his mentorship in CF care and collaboration with this project. The authors also thank Dr Henry Dorkin of Boston Children's Hospital. The authors also thank the faculty of the Partners' Clinical Process Improvement Leadership Program (CPIP) for their instruction and coaching in QI methodology.

Contributors BLB and ASJ planned the study, while IPN, BMC and LMY provided feedback and expert knowledge in CF care (IPN, LMY), lung transplantation (IPN), and quality improvement methodology (BMC). BLB and ASJ performed the data collection. BLB analysed the data and prepared the first draft of the manuscript. The manuscript was critically reviewed and approved by all authors.

Funding Cystic Fibrosis Foundation, Clinical Fellowship Grant (BARTLE19D0). This funding supported the clinical and research fellowship position of BB.

Competing interests None declared.

Patient and public involvement Patients and/or the public were involved in the design, or conduct, or reporting, or dissemination plans of this research. Refer to the Methods section for further details.

Patient consent for publication Not required.

Provenance and peer review Not commissioned; externally peer reviewed.

Data availability statement Data are available upon request.

Open access This is an open access article distributed in accordance with the Creative Commons Attribution Non Commercial (CC BY-NC 4.0) license, which permits others to distribute, remix, adapt, build upon this work noncommercially, and license their derivative works on different terms, provided the original work is properly cited, appropriate credit is given, any changes made indicated, and the use is non-commercial. See: http://creativecommons.org/ licenses/by-nc/4.0/.

ORCID iD

Bethany L Bartley http://orcid.org/0000-0002-9043-6697

\section{REFERENCES}

1 Ramos KJ, Quon BS, Heltshe SL, et al. Heterogeneity in Survival in Adult Patients With Cystic Fibrosis With FEV $1<30 \%$ of Predicted in the United States. Chest 2017;151:1320-8.

2 Ramos KJ, Smith PJ, McKone EF, et al. Lung transplant referral for individuals with cystic fibrosis: cystic fibrosis Foundation consensus guidelines. J Cyst Fibros 2019;18:321-33.

3 Cystic Fibrosis Foundation. Cf care center visits. Available: https:// www.cff.org/Life-With-CF/Treatments-and-Therapies/TreatmentPlan/CF-Care-Center-Visits/ [Accessed 23 Mar 2020].

4 Ramos KJ, Somayaji R, Lease ED, et al. Cystic fibrosis physicians' perspectives on the timing of referral for lung transplant evaluation: a survey of physicians in the United States. BMC Pulm Med 2017;17:21-9.

5 Bartley BL, Schwartz CE, Stark RB, et al. Lung transplant referral practice patterns: a survey of cystic fibrosis physicians and general pulmonologists. BMC Pulm Med 2020;20:58.

6 Ramos KJ, Hobler MR, Engelberg RA, et al. Addressing lung transplant with adults with cystic fibrosis: a qualitative analysis of patients' perspectives and experiences. J Cyst Fibros 2019;18:416-9.

7 Langley GJ, Moen RD, Nolan KM, et al. The improvement guide: a practical approach to enhancing organizational performance. Hoboken, NJ: John Wiley \& Sons, Inc, 2009: 131-7.

8 Middleton PG, Mall MA, Dřevínek P, et al. Elexacaftor-TezacaftorIvacaftor for cystic fibrosis with a single Phe508del allele. N Engl J Med 2019;381:1809-19.

9 McKone EF, Borowitz D, Dřevínek P, et al. Long-Term safety and efficacy of ivacaftor in patients with cystic fibrosis who have the Gly551Asp-CFTR mutation: a phase 3, open-label extension study (persist). Lancet Respir Med 2014;2:902-10.

10 Taylor-Cousar JL, Munck A, McKone EF, et al. Tezacaftor-Ivacaftor in patients with cystic fibrosis homozygous for Phe508del. N Engl J Med 2017;377:2013-23.

11 Volkova N, Moy K, Evans J, et al. Disease progression in patients with cystic fibrosis treated with ivacaftor: data from national US and UK registries. J Cyst Fibros 2020;19:68-79. 